\title{
Application of aquatic plants in urban ecological construction of Kunming
}

\author{
CAO Yongqiong ${ }^{1, *}$, She Lina ${ }^{1}$, WV Yumei ${ }^{2}$, ZHAO Feng $^{2}$ \\ ${ }^{1}$ Research Department, Kunming University, Kunming, Yunnan, China \\ ${ }^{2}$ College of Agronomy and Life Sciences, Kunming University, Kunming, Yunnan, China
}

\begin{abstract}
Aquatic plants play an important role in urban construction. According to the application status of aquatic plants in urban construction of Kunming, It is suggested that aquatic herbs should be used as the main plant to optimize the allocation; Reasonable harvest management should be carried out; Effective control of aquatic plant biomass and other measures. To construct a biodiversity aquatic plant community. Accelerate the pace of urban ecological construction.
\end{abstract}

\section{Introduction}

Kunming is a biodiversity city. The goal of urban construction is to improve the quality of ecological environment. It can set an example for the construction of other surrounding cities, take the role of benchmarking, and drive the development of Yunnan. At present, the investment in wetland and waterscape has been increased in the urban construction of Kunming. In addition to the waterscape of various parks, wetlands and residential areas, many large waterscapes are planned and constructed in the main urban area of Kunming, such as Niulanjiang waterfall Park in the green land with a total land area of $480 \mathrm{mu}$ and a water area of $209 \mathrm{mu}$ in the north of Kunming; central waterscape of Wujiaba area with a total planning area of $987 \mathrm{mu}$ and a water area of $225 \mathrm{mu}$; planning area of $228 \mathrm{mu}$ and The water area of the lake is about $79 \mathrm{mu}$, and the water landscape area is $2.5 \mathrm{mu}$. The water landscape of the new town park, Expo Park, central business district (eye of Kunming) and the Central Park of Chenggong New Area. Urban landscape is "born and prospered because of water". Increasing the investment of waterscape in urban ecological construction can make the city more vigorous. As the main body of waterscape, aquatic plants are cultivated and applied more and more, and the landscape effect is getting better and better. The improvement of ecological environment, regulation and promotion effect is becoming more and more obvious[1].

\section{Application of aquatic plants in ecological construction}

The key link of aquatic plants in ecological construction is the selection and collocation of species, and the optimization path is the three-dimensional spatial configuration of water area and the combination configuration of different seasons. According to the local climate and environmental conditions, aquatic plants with ecological functions are introduced. Through reasonable design, various, multi-layer, efficient and stable communities are configured, so as to establish a stable water environment ecosystem with self purification ability.

\subsection{Selection and collocation of suitable species of aquatic plants}

The selection and collocation of suitable aquatic plants play an important role in building a healthy and stable ecosystem. On the one hand, we should consider the morphological characteristics, growth conditions and ecological functions of aquatic plants, on the other hand, we should consider the stability of community structure of different aquatic plants, the landscape of three-dimensional space, and the suitability and anti-interference ability of aquatic plants in different seasons. In the early stage of community construction, plants with strong resistance and adaptability should be selected. With the gradual formation of the community, different life forms of plants can be configured to enrich the species diversity of aquatic plants and optimize the community structure, so as to maintain the stability of the ecosystem.

\subsection{Planting density of aquatic plants}

The planting density of aquatic plants will affect the interspecific competition and landscape effect. In general, the planting density of the plants with high height and rapid propagation is smaller, and the method of piece planting and block planting is used. On the contrary, the planting density is larger, and full planting is often used.

*Corresponding author:a1146697549@qq.com 


\subsection{Aquatic plant community construction and management after configuration}

After the completion of the construction and configuration of aquatic plants, it is necessary to formulate targeted harvesting and removal management measures for the aquatic plant community, timely and effectively adjust the community structure, maintain the community function, and always keep the aquatic plant ecosystem in the best operating state, so as to realize its ecological and social benefits.

\section{Suggestions on the application of aquatic plants in Kunming}

\subsection{Select suitable aquatic plant species for optimal allocation}

\subsubsection{Give full play to the ecological function of aquatic plants in urban construction}

Plant configuration is the main body of urban ecological construction, and aquatic plants are the most difficult and important part of plant configuration. Only by selecting appropriate aquatic plants for reasonable configuration, can the urban ecological function be more effectively played and contribution be made to urban construction and development.

Kunming is rich in natural resources, suitable climate conditions, a variety of aquatic plant species, select some suitable for urban ecological construction of aquatic plant species, reasonable allocation in a variety of waterscape, can optimize the urban ecosystem, reduce pollution, improve the quality of urban ecological environment, accelerate the pace of building a civilized city, give full play to the role of economic free trade zone.

\subsubsection{Improve and optimize the configuration scheme of aquatic plants}

The optimal allocation of aquatic plants in urban ecological construction of Kunming can give full play to the naturalness and functionality of aquatic plants, reduce the cost of management, help to analyze the scientificity and rationality of the planning content, judge the feasibility of urban planning scheme and countermeasures, and pay attention to the comprehensive benefits of Kunming Urban Ecosystem, improve and optimize the allocation and management of aquatic plants in urban ecological construction To realize the sustainable development of Kunming City and ecology.

The investigation found that in the construction of Kunming waterscape, woody plants such as willow, Chinese fir, Larix and Taxodium with good water resistance are used on the bank, and herbs such as emergent plants + submerged plants + floating plants are used in the water, which can form a better aquatic plant ecological environment [2]. The species and growth characteristics of aquatic herbs commonly used in Kunming are shown in Table 1.

Table 1 Types and growth characteristics of aquatic herbs commonly used in Kunming.

\begin{tabular}{lll}
\hline \multicolumn{1}{c}{ type } & \multicolumn{1}{c}{ Life characteristics } & \multicolumn{1}{c}{ Plant species } \\
\hline Emergent & The root or underground stem goes deep into the & Lotus 、Iris 、Typha、reed Z Zizania \\
plant & sediment, and the stem and leaf are higher than the & latifolia 、 Canna 、Hardy canna 、 \\
& water surface. & Eclipta、Sedge
\end{tabular}

Floating leaf When the roots are buried in the soil, the leaves plant float on the water, and the petioles elongate with Water lilies、Tian Zicao、ShuiHe the depth of the water.

Floating The leaves float on the surface of the water, and the plants plants can drift with the wind

Submerged macrophyte
The roots are fixed in the underwater soil or floating in the water, and the plants are completely or mostly submerged in the water.
Water hyacinth、Duckweed, water hyacinth

Vallisneria 、 hydrilla verticillata 、 Myriophylla、Ceratophyllum

\subsection{Appropriate cultivation and management measures for aquatic plants}

The cultivation methods of aquatic plants include natural planting, container planting, planting bed planting and floating island planting. They have their own advantages and can be selected according to different locations and regions. For example, floating island planting is the most scientific and advanced planting method, with simple 
management, easy operation, low cost, and good effect in some closed waterscape.

Kunming is commonly used in natural planting and planting bed planting, both simple operation, complex management, every year in autumn and winter cleaning and harvesting, spring planting, in order to effectively control growth, form a three-dimensional space landscape effect, to achieve the goal of waterscape ecology.

\subsection{Establish a correct evaluation system for the healthy growth of aquatic plants}

It is generally believed that a healthy water environment ecosystem should have six characteristics, namely, self balance, disease-free, diversity, resilience, vitality and the ability to maintain the balance of system combination ${ }^{[3-4]}$. For most urban waterscape, aquatic plant is an important index to evaluate the vitality, diversity and resilience of waterscape. Therefore, many waterscape health assessments use the index of aquatic plant coverage to determine the health status. It is found that the coverage rate of $20-30 \%$ is the most suitable for the growth of aquatic plants and the effect of waterscape is good.

\subsection{Effective control of aquatic plant biomass and reasonable harvesting management}

\subsubsection{Control of aquatic plant biomass}

The growth cycle of plants can be divided into germination period, growth period and decline period. The two key periods of biomass management of aquatic plants are growth period and early decline period. During the growth period, it mainly regulates the biomass of different aquatic plants, promotes the formation of nutrient level stable ecosystem, avoids excessive growth and density, and threatens the health of aquatic animals; at the initial stage of decline, it is necessary to control the biomass of aquatic plants, consider the basic demand for biomass for germination in the second year, and reduce the secondary pollution caused by plant decomposition.

The evaluation method of suitable biomass of aquatic plants in different growth periods was put forward, which provided practical reference for maintenance and management of aquatic plants in growth period and harvesting management of aquatic plants in decline period.

\subsubsection{Reasonable arrangement of annual harvest times and harvest season}

At present, mechanical or manual harvesting is the most widely used method to control the biomass of aquatic plants. Appropriate harvesting frequency and area can not only consume the excess nutrients in the water environment, but also benefit the recovery and growth of aquatic plants, and continuously purify and stabilize the water quality. Like bitter grass, It was found that the comprehensive benefit of water quality improvement was the best when the biomass of Vallisneria was reduced to $118 \mathrm{~g} / \mathrm{m} 2$ under $65 \%$ harvesting rate ${ }^{[5]}$.

The harvesting period of aquatic plants needs to be comprehensively considered according to the environmental conditions, climate characteristics, plant growth rules and water quality of their growing areas. Most of the aquatic plants planted in the current water environment are emergent plants, which can obtain a good growth environment and grow fast because of their low root depth in the water.

Kunming harvest once a year is the most ideal, can let the aquatic plants in the best growth state. If the harvesting frequency is too high, it will increase the workload of managers, affect the canopy density of aquatic plants, improve the environmental temperature of aquatic plants, increase the loss of water, and accelerate the withering and death of aquatic plants; if the harvesting frequency is too low, the plants will naturally enter dormancy, and the accumulated nutrients in their bodies are insufficient, which will affect their growth quality and the amount of withered grass There are too many seeds to sprout for the second time.

According to the growth law of plants, the harvest season is arranged, so as not to affect the normal growth of plants as far as possible, so as to ensure that they can safely overwinter. Aquatic plants in Kunming begin to sprout in the middle and late February every year, and grow vigorously from the beginning of June to the middle and late August, and most of them enter the late growth stage in early September. For many growing plants that need second harvest, the first harvest should be carried out at the end of August. About a month after harvest, the plants will enter the second vigorous growth period, which can extend the growth cycle of plants and lay a solid foundation for their safe overwintering. Considering the canopy situation of plants, if the first harvest time is earlier, it will directly affect the growth of plants However, if the first harvest time is too late, many plants will enter the seed setting stage, which means that the plants will stop growing and wither quickly, which will affect the landscape effect of the wetland, make it unable to achieve the second vigorous growth, and will continue the negative impact to winter.

To sum up, aquatic plants can purify water, with the characteristics of low consumption, high efficiency and safety; they can absorb various suspended substances in water, improve water clarity, and increase underwater light conditions; after harvest, they can transfer nutrients such as nitrogen, phosphorus and potassium, and improve water ecological environment and ecosystem. To explore the application of aquatic plants in urban ecological construction of Kunming can provide a certain reference for the establishment of urban ecosystem evaluation system in the future, build a reasonable aquatic plant urban ecosystem, facilitate decision-makers and management departments to measure and compare the planning schemes, and reduce the cost of urban ecological planning and construction Mistakes in work, reduce waste. 


\section{Reference}

1. Li Donglin, Wang Lei, Ding Jingjing, et al. Ecological function and resource application of aquatic plants [J]. Wetland Science, 2011(3): $290-296$

2. Li Wenchao. Sedimentation promoting effect of aquatic plants and phosphorus deposition in Eastern Taihu Lake $[\mathrm{J}]$. environmental science, 1997,18(3):9-12.

3. Costanza R, Norton B, Haskell B. Ecosystem health new goals for environmental management [M]. Washington DC: Island Press, 1992:18-24.

4. Jorgensen SE. A systems approach to the environmental analysis of pollution minimization [M]. New York: Lewis Publisher, 1999:20-53.

5. Zhang Laijia, ye Chun, Li Chunhua, et al. Effects of different biomass of Vallisneria on water quality in different stages of life cycle [J]. Environmental Science in China, 2013,33(11):2053 -2 